\title{
Study of total instantaneous friction torque of a compression ignition (CI) engine: A numerical and experimental approach
}

\author{
Seddak Mohammed*** and Lakhdari A. Amina* \\ * Mechanical Engineering Department, Mechanical Faculty, University of Science and Technology Oran - Mohamed Boudiaf. BP 1505 \\ El Mnaouar, Oran 31000, Algérie \\ ** Environmental Technologies Research Laboratory, National Polytechnic School of Oran Maurice Audin, Oran, Algeria \\ *,**Corresponding Author: m_seddak@univ-usto.dz
}

Submitted : 10/06/2019

Revised :24/06/2021

Accepted :05/07/2021

\begin{abstract}
To be able to provide an accurate estimate of the effective torque, friction losses must be modeled. The details of a model that predict the total instantaneous friction torque for compression ignition engines are described. The model is based on a combination between the dynamic model of the crankshaft and the thermodynamic model. The total instantaneous friction torque is determined via the instantaneous measurements or numerical predictions of the gas pressure in the combustion chamber, the speed of rotation of the crankshaft, and load torque. The comparison between the experimental data and the results of the numerical simulation shows a good agreement.
\end{abstract}

Keywords: Diesel engines; Instantaneous friction torque; Crankshaft dynamic; Thermodynamic model; Instantaneous engine speed.

\section{NOTATIONS}

$\theta \quad$ Crankshaft angular position, (rad)

$\dot{\theta} \quad$ Instantaneous crankshaft speed, $(\mathrm{rad} / \mathrm{s})$

$\ddot{\theta} \quad$ Instantaneous crankshaft acceleration, $\left(\mathrm{rad} / \mathrm{s}^{2}\right)$

$\gamma \quad$ Specific heat ratio, dimensionless

$\Gamma \quad$ Torque, (N.m)

$A_{p} \quad$ Piston surface, $\left(\mathrm{m}^{2}\right)$

$A_{h} \quad$ Heat transfer area, $\left(\mathrm{m}^{2}\right)$

$C_{p} \quad$ Constant pressure specific heat, $(\mathrm{kJ} / \mathrm{kg} \mathrm{K})$

$C_{v} \quad$ Constant volume specific heat, $(\mathrm{kJ} / \mathrm{kg} \mathrm{K})$

$D \quad$ Cylinder bore, (m)

$J \quad$ Moment of inertia, $\left(\mathrm{kg} \mathrm{m}^{2}\right)$ 
$l \quad$ Connecting rod length, $(\mathrm{m})$

LHV Lower heating value, $(\mathrm{kJ} / \mathrm{kg})$

$m_{c y l} \quad$ Mass of in-cylinder mixture, $(\mathrm{kg})$

$m_{f} \quad$ Mass of injected fuel, $(\mathrm{kg})$

$N \quad$ Engine speed, (rpm)

$p_{c y l} \quad$ In-cylinder pressure, (bar)

$Q \quad$ Heat transfer, $(\mathrm{kJ})$

$Q_{\text {in }} \quad$ Heat added from burning fuel, $(\mathrm{kJ})$

$Q_{d} \quad$ Integrated energy release for diffusion combustion phases, $(\mathrm{kJ})$

$Q_{\text {loss }} \quad$ Heat losses, (kJ)

$Q_{p} \quad$ Integrated energy release for premixed combustion phases, (kJ)

$r \quad$ Crank radius, $(\mathrm{m})$

$R_{g} \quad$ Universal gas constant, $(\mathrm{kJ} / \mathrm{kg} . \mathrm{K})$

$S \quad$ Engine stroke, $(\mathrm{m})$

$T_{c y l} \quad$ In-cylinder gas temperature, $(\mathrm{K})$

$T_{w} \quad$ Cylinder temperature, $(\mathrm{K})$

$V_{c y l} \quad$ Cylinder volume, $\left(\mathrm{m}^{3}\right)$

$V_{c} \quad$ Clearance volume, $\left(\mathrm{m}^{3}\right)$

$Z_{c y l} \quad$ Number of cylinders, dimensionless.

\section{INTRODUCTION}

Rapid improvements in power levels and computing capabilities lead to great breakthroughs in many technological areas, especially during the last two decades. With the help of current computer machines and codes, large-scale mechanical models can be analyzed more efficiently and reliably. Areas of research that have benefited greatly from these advances are the fields of engine dynamics and thermodynamics, mainly because of their practical importance and great interest of the automotive industry to reduce production costs. On the other side, the analysis and measurement of friction losses in the engine are not solved satisfactorily. On the one hand, difficulty lies in direct accurate measurement and, on the other hand, in interpreting the complex interactions of the different parameters.

The difficulties of analysis and prediction of total friction losses result from the fact that the total loss in an engine results from the losses produced in different engine parts that do not react in the same way to pressure, speed, and load variations (Wong et al., 2016). The control of these losses is therefore of immediate practical importance. Therefore, a low level of friction allows the engine to run at a high speed and develops great power. The reduction of friction losses improves the performance parameters of the engine.

The three main components of Engine friction are as follows: rubbing friction, pumping (or gas exchange) losses, and ancillary losses. Ancillary losses originate from driving engine ancillaries such as water, oil, and fuel pumps.

Several methods of measuring the power lost by friction in an engine are used. They can be classified into 4 groups (Heywood, 1988): 


\section{The Willan's Method}

This method consists of drawing the curve giving the specific consumption as a function of the Mean Effective Pressure $(M E P)$ at a fixed speed. The extrapolation of the curve obtained in the domain of negative MEP allows then to determine the power lost by friction. This method of measuring the Brake Mean Effective Pressure (BMEP) poses virtually no experimental problem. However, extrapolation can be difficult, because the curve obtained is not a straight line.

\section{Motoring Tests}

This method involves driving the engine without combustion by means of an electric motor whose power consumption is measured at the desired speed.

The power of the electric motor also includes losses by transfer. However, this measurement only takes into account the influence of speed on friction; also, the results obtained are difficult to extrapolate for a normal running engine where the variation of the load must be taken into account, and the thermal equilibrium of the loaded engine must be achieved.

\section{The Morse Test}

This method (Morris et al., 2013) consists in measuring the power lost by friction on an engine running by successively eliminating the combustion on each cylinder either by disconnecting the spark plug in the case of a spark ignition engine or the injector in the case of a diesel engine. This method has the drawback of modifying the thermal equilibrium of the engine if the break is too long or if the engine is stopped to disconnect the spark plug or injector.

\section{4) The Indicator Method}

On the one hand, this method consists of calculating directly the indicated work $\left(W_{i}\right)$ to from the simultaneous measurement of the gas pressure of the combustion and the volume they occupy at all times and, on the other hand, measuring the effective work $\left(W_{e}\right)$ through the brake placed at the end of the shaft. The mechanical losses by friction are then equal to the difference of these two works.

Two categories of engine friction calculation models described in the literature are as follows: Crankshaft Resolved Models and Mean Cycle Correlations. The first models allow instantaneous evaluation of friction losses at any time of the engine cycle. They can be subdivided into models using analytical and semiempirical correlations, and more models were derived from the first principles solving the Reynolds equation of lubrication (Fang et al., 2017). The authors (Ciulli et al. 1996) have studied instantaneous friction models using cylinder pressure and engine speed measurements to calculate the different friction components. In this case, the analytical equations were used. A friction model is based on a study (Ciulli et al. 1996) to study the effect of maximum cylinder pressure on engine friction. A large influence of the load and the rotational speed on the Friction Mean Effective Pressure $(F M E P)$ was studied, as the effect of the combustion pressure was relatively low. This has been attributed to the fact that the engine friction torque is affected by the maximum cylinder pressure around the TDC position only (Kouremenos et al., 2001). The values obtained from the FMEP of the engine (averaged over a cycle of the engine) are in good agreement with the measured values. A semiempirical correlation was also obtained taking into account the effect of the engine speed $\left(V_{p}\right.$ : the average piston speed), the Indicated Mean Effective Pressure (IMEP), and the maximum cylinder pressure $\left(P_{\max }\right)$.

Thring (Thring, 1992) investigated the effect of design variation on friction in a two-liter four-cylinder gasoline engine. The model was obtained from the first principles and for the adjustment of empirical constants. The reference 
(Thring, 1992) neglected the limit friction at the end of the stroke for the entire piston, due to the relatively low speed of the piston and therefore low power dissipation associated with these points in the engine cycle. The changes in the bearing shape ratio resulted in significant reductions in friction, particularly for the valve train. The changes to the camshaft bearings reduced total friction of engine by $2.5 \%$, and a maximum reduction of $1 \%$ was achieved with changes to the main bearing design. The predictions of significant increases in friction due to higher cylinder pressures, particularly in the case of piston rings and main bearings (Thring, 1992), are in contrast to the results reported by Kouremenos et al. (2001) on the effects of maximum cylinder pressure. On the other hand, the authors of the reference (Miura et al., 1989) have carried out experimental measurements, which show that the friction averaged of main bearing over one cycle is almost independent of the load. The engine load has a significant effect on bearing friction but only on a small fraction of the engine cycle. However, the load imposes the size of the bearing, which has a strong impact on the friction. The work (Leong, 2004) has shown that the tension on the piston ring and the cylinder pressure have a negligible influence on the friction of the piston. Leong associated the latter with the small area behind the rings that is subject to an increase in gas load. The majority of researchers suggest that the effect of engine load on FMEP is low.

An instantaneous friction model was developed by Meng et al. (2016); this model can predict the thickness of the oil film on the friction surfaces and the transition between the different lubrication regimes. The authors of the reference (Meng et al., 2016) adopted this approach for the assembly of pistons, but for plain bearings, they used analytical solutions developed by (Livanos et al., 2006). The authors of the reference (Zweiri et al., 1999) proposed a formulation for the calculation of the friction torque of the set of valves, as well as a model of friction of the crank of a diesel engine. The equations of the model are analytically derived and are based on dynamic analyzes and the Reynolds equation. The model takes into account the variation of the viscosity of the oil. To simulate the transient behavior of the engine, models of friction and engine dynamics versus crankshaft angle are used together by Zweiri et al. (1999). These models are used for online diagnostic and control applications. On the other hand, these models based on the crankshaft angle require the determination of many parameters and constants, which can be difficult to determine. The comparisons of engine performance simulations with both types of friction models (crankshaft angle and averaged models) show only slight differences in predictions of temperature, pressure, etc. (Holmberg et al.,2012).

The friction of the engine is a contribution of friction components independent of the engine speed (limit friction) other proportional to driving regime (hydrodynamic friction) and finally proportional to the square of the speed (turbulent dissipation). The models developed by (Bishop,1964 \& Patton et al., 1989) are typical examples of this type of model. A comparison between the predictions of friction of 10 different models applied to a diesel engine four-cylinder direct injection four-stroke. The important difference between the results shows the difficulty of obtaining consistent friction predictions. However, the study (Holmberg et al., 2012) explains that most formulas cannot be directly compared because they are derived for different engines and different operating conditions (diesel or gasoline, mono or multicylinder configurations, driving conditions or ignition, including or excluding pumping losses, etc.). The authors of reference (Holmberg et al., 2012) showed that the total friction of the engine was reduced by 15 to $20 \%$ over a period of 20 years; the reason is the reduction of piston friction and pumping losses. To predict friction losses at cooler temperatures, a calibration of lubricant viscosity with temperature was added. A modified version of Patton's model was also developed by (Taraza et al., 2007).

The models developed to describe the internal combustion engine cycle are generally divided into two main groups, depending on the physical basis used to present the fundamental equations. These are models of thermodynamics and fluid dynamics. In the thermodynamic models, the terminology often used is the zerodimensional model with single and multizones. The single-zone models are based on the conservation equations of mass and energy, using the first law of thermodynamics and no spatial resolution, because all thermodynamic properties are considered uniform. Only one control volume is considered. In multizone models, the combustion chamber is divided into several zones, with uniform thermodynamic properties for each zone. The first law of 
thermodynamics applies to each of these control volumes with appropriate boundary conditions. The mathematical equations are a set of differential equations whose independent variable is the time or angle of the crankshaft. The quasidimensional models are a particular type of these models.

The fluid dynamics models are also known as Computational Fluid Dynamics (CFD) models. These are multidimensional models based on solving the conservation equations for mass, momentum, and energy at any point on the engine cylinder. To these equations are also added transport equations describing the chemical species considered. Mathematically, all these equations constitute a system of partial differential equations. Time and spatial coordinates are considered as independent variables; it is therefore possible to obtain a complete spatial resolution of the properties of the gases in the cylinder.

In this paper, the dynamics and thermodynamics models of the engine are combined, and a model is developed and used to predict the variations of the total instantaneous friction in an engine cycle as a function of crankshaft angle. The thermodynamic model is used to predict cylinder pressure. This model treats the conservation equations of energy and mass with the submodels for combustion and heat transfer. The calculations in the cycle are performed for each crank angle. The conservation equations of mass and energy, property relations, and the laws of perfect gases are solved in the crank angle range. A single-zone combustion model is used to simulate the theoretical fuel combustion rate. The cylinder is considered as a single volume of control, and the temperature and the pressure are homogeneous.

The dynamic model of the engine is based on the analysis of instantaneous variations of the angular velocity of the crankshaft resulting from the combination of the pressure created by the combustion gases, the inertia of the moving parts, and the applied load. It allows determining the total instantaneous friction torque in the engine.

A study of total instantaneous friction should allow a better understanding of the phenomenon of friction in order to reduce it where it is most important.

\section{IN-CYLINDER MODELING}

In this study, the gas torque is estimated without recourse to the measurement of the cylinder pressure because of the difficulties of the measurement of this variable. The idea is to exploit a fast and precise thermodynamic model. The innovative idea in this work is the calculation of the specific heat ratio $\gamma$ of the thermodynamic processes at each degree of the crankshaft. The total differential of the cylinder pressure equation is

$\frac{d p_{c y l}}{d \theta}=\frac{\gamma\left(T_{c y l}\right)}{V_{c y l}} \frac{d V_{c y l}}{d \theta} p_{c y l}+\frac{\gamma\left(T_{c y l}\right)-1}{V_{c y l}} \frac{d Q}{d \theta}$

where $\gamma=\frac{C_{p}}{C_{v}}$ and $R_{g}=C_{p}-C_{v}$

The net heat release is

$\frac{d Q}{d \theta}=\frac{d Q_{\text {in }}}{d \theta}-\frac{d Q_{\text {loss }}}{d \theta}$

where $\frac{d Q_{i n}}{d \theta}$ is the rate of the heat input, and $\frac{d Q_{\text {loss }}}{d \theta}$ is the rate of heat loss through cylinder walls. 
The total of heat input to the cylinder of fuel in one cycle is

$Q_{\text {in }}=m_{f} L H V$

The heat release $\frac{d Q_{i n}}{d \theta}$ is calculated by a dual Wiebe function (Iserman, 2014):

$\frac{d Q_{i n}}{d \theta}=a\left(\frac{Q_{p}}{\theta_{p}}\right) m_{p}\left(\frac{\theta}{\theta_{p}}\right)^{m_{p}-1} \exp \left(-a\left(\frac{\theta}{\theta_{p}}\right)^{m_{p}}\right)+a\left(\frac{Q_{d}}{\theta_{d}}\right) m_{d}\left(\frac{\theta}{\theta_{d}}\right)^{m_{d}-1} \exp \left(-a\left(\frac{\theta}{\theta_{d}}\right)^{m_{d}}\right)$

where $d$ and $p$ refer to diffusion and premixed phases of combustion. The parameters $\theta_{p}$ and $\theta_{d}$ represent the duration of the premixed and diffusion combustion phases. Also, $Q_{p}$ and $Q_{d}$ represent the integrated energy release for premixed and diffusion phases, respectively. The constants are $a=6.9, m_{p}=4$ and $m_{d}=1.5$ (Seddak et al., 2018).

The rate of the heat loss is

$\frac{d Q_{\text {loss }}}{d \theta}=h A_{h}(\theta)\left(T_{c y l}-T_{w}\right) \frac{1}{\omega}$

The Woschni model is used to calculate the convective heat transfer coefficient (Sakhrieh et al., 2010 \& Ferguson et al., 2001):

$h=3.26 D^{-0.2} p^{0.8} T_{c y l}{ }^{-0.55} \omega^{0.8}$

where

$\omega(\theta)=2.28 \bar{U}_{p}+C_{1} \frac{V_{d} T_{g r}}{p_{r} V_{r}}\left(p(\theta)-p_{m}\right)$

where

$$
\left\{\begin{array}{c}
C_{1}=0 \text { for compression phase, } \\
C_{1}=0.00324 \text { for combustion and expansion phases }
\end{array}\right.
$$

The operating variables at closing of the intake valve are $V_{r}, T_{g r}$, and $p_{r}$ and $p_{m}$ are the pressure at the same position to obtain the pressure $p$ without combustion (pressure values in cranking). $\overline{U_{p}}$ is calculated as

$\overline{U_{p}}=\frac{2 N S}{60}$

The following equations give instantaneous displacement, cylinder volume, and area (Pulkrabek, 2004):

$$
\begin{aligned}
& x(\theta)=l+r(1-\cos (\theta))+\left(l^{2}-r^{2} \sin ^{2}(\theta)\right)^{1 / 2} \\
& V(\theta)=V_{c}+\frac{\pi D^{2}}{4} x(\theta) \\
& \mathrm{A}_{\mathrm{h}}(\theta)=\frac{\pi \mathrm{D}^{2}}{4}+\frac{\pi \mathrm{DS}}{2}\left(\mathrm{r}+1-\cos (\theta)+\left(\mathrm{r}^{2}-\sin ^{2}(\theta)\right)^{1 / 2}\right)
\end{aligned}
$$


The stroke $(S)$ and crank radius are related by

$S=2 r$

Sonntag (Sonntag et al., 1998) has described an equation of the variation of the specific heats of air in a temperature range between 300 and $3500 \mathrm{~K}$. The air is assumed as an ideal gas.

$C_{p}=2.506 \times 10^{-11} T_{c y l}^{2}+1.454 \times 10^{-7} T_{c y l}^{1.5}-4.246 \times 10^{-7} T_{c y l}+3.162 \times 10^{-5} T_{c y l}^{0.5}+1.3303-$

$1.512 \times 10^{4} T_{c y l}{ }^{-1.5}+3.063 \times 10^{5} T_{c y l}{ }^{-2}-2.212 \times 10^{7} T_{c y l}{ }^{-3}$

The fourth-order Runge-Kutta method is used to solve equation (1) and obtain the cylinder pressure. The initial and boundary conditions are pressure $=P_{0}$ atmospheric pressure and temperature $=T_{0}$ ambient temperature.

The state equation is used to calculate the gas temperature in the cylinder:

$T_{c y l}=\frac{p_{c y l}(\theta) V(\theta)}{m_{c y l} R_{g}\left(T_{c y l}\right)}$

\section{ENGINE CRANKSHAFT DYNAMIC MODEL}

The dynamic model of the engine used in this study must be capable of predicting the indicated torque according to the instantaneous speed of the crankshaft and the load torque applied to the engine shaft. The average speed of the crankshaft is constant during an engine cycle; however, the instantaneous speed exhibits marked fluctuations in view of the sudden variations in the pressure in the cylinder and the forces acting on the piston. Also, to best describe these variations, it is better to define the model in the angular domain.

The rigid body model is a simple model and will require less computation time. This model is used to calculate the total torque. The equilibrium equation describes the crankshaft torque (Kiencke et al., 2000):

$\mathrm{J}(\theta) \ddot{\theta}=\Gamma_{\text {total }}(\theta)=\Gamma_{\text {gas }}(\theta)+\Gamma_{\text {mass }}(\theta)+\Gamma_{\text {load }}(\theta)+\Gamma_{\text {fr }}(\theta)$

Reciprocating mechanisms have variable inertia due to the change of geometry through a crank revolution. The moment of inertia is as follows (Kiencke et al., 2000):

$J(\theta)=m_{r o t} \cdot r^{2}+m_{o s c} \cdot \sum_{j=1}^{Z_{c y l}}\left(\frac{d x}{d \theta}\right)^{2}$

In Kiencke et al. (2000), a two-mass approach is presented as a model of the connecting rod. The oscillating mass at each cylinder is

$m_{\text {osc }}=m_{\text {piston }}+m_{c r} \cdot \frac{l_{\text {osc }}}{l}$ 
with $l_{\text {osc }}=\frac{2 l}{3}$

and the rotational mass of the crankshaft portion at one cylinder

$\frac{m_{r o t}}{Z_{c y l}}=\frac{m_{c r a n k}}{Z_{c y l}}+m_{c r} \cdot \frac{l_{r o t}}{l}$

with $l_{\text {rot }}=\frac{l}{3}$

The indicated torque $\Gamma_{\text {indicated }}$ or $\Gamma_{\text {gas }}$ is a function of the pressure $p$ and the geometry of the engine. This torque is expressed as

$$
\Gamma_{g a s}(\theta)=\left(p_{c y l}(\theta)-p_{0}\right) A_{p} \frac{d x}{d \theta}=p_{g a s}(\theta) A_{p} \frac{d x}{d \theta}
$$

The gas pressure is defined as $P_{\text {gas }}=p_{c y l}(\theta)-p_{0}$.

$p_{0}:$ the counteracting pressure $\left(p_{0=} p_{a t m}\right)$

The engine reciprocating components motion (piston and connecting rod) generates the mass torque $\Gamma_{\text {mass }}$ or reciprocating torque:

$\Gamma_{\text {mass }}(\theta, \dot{\theta}, \ddot{\theta})=-\left(m_{\text {piston }}+m_{c r}\right) \frac{d x}{d \theta} \frac{d^{2} x}{d \theta^{2}} \dot{\theta}^{2}-\left(m_{\text {piston }}+m_{c r}\right)\left(\frac{d x}{d \theta}\right)^{2} \ddot{\theta}$

where $m_{c r}$ and $m_{\text {piston }}$ are connecting rod and piston mass, and the functions $\frac{d x}{d \theta}$ and $\frac{d^{2} x}{d \theta^{2}}$ are the first and second derivative of stroke (displacement) of piston, respectively.

The derivatives of the piston displacement are

$V_{p}=\frac{d x}{d \theta}=r\left(\sin (\theta)+\frac{r}{l} \cdot \frac{\sin (\theta) \cos (\theta)}{\sqrt{1-\frac{r^{2}}{l^{2}} \sin ^{2}(\theta)}}\right)$

$\frac{d^{2} x}{d \theta^{2}}=r\left(\cos (\theta)+\frac{\frac{r}{l}\left(\cos ^{2}(\theta)-\sin ^{2}(\theta)\right)+\frac{r^{2}}{l^{2}} \sin ^{4}(\theta)}{\left(\sqrt{1-\frac{r^{2}}{l^{2}} \sin ^{2}(\theta)}\right)^{3}}\right)$

$\Gamma_{\text {load }}$, in equation (22), is the load (resistance) torque, which is usually expressed by

$$
\Gamma_{\text {load }}(\theta)=c+k \omega^{s}
$$

$\omega:$ Angular velocity $\left(s^{-1}\right)$ 
For a linear load (electric brake, generator), $c=0$,

$k>0$ and $s=1$ (Rakopoulos et al., 2009).

Equation (23) is the result of the left-side integration of equation (14), and $\left.\dot{\theta}\right|_{\theta}$ indicates the instantaneous crankshaft speed for the crank angle $\theta$.

$$
\begin{gathered}
\int_{\theta-\Delta \theta}^{\theta} J \ddot{\theta} d \theta=J \times \int_{\theta-\Delta \theta}^{\theta} \frac{d \dot{\theta}}{d t} d \theta=J \times \int_{\theta-\Delta \theta}^{\theta} \frac{d \theta}{d t} d \dot{\theta}=J \times \int_{\theta-\Delta \theta}^{\theta} \dot{\theta} d \dot{\theta}=\frac{1}{2} J\left[\left(\left.\dot{\theta}\right|_{\theta}\right)^{2}-\right. \\
\left.\left(\left.\dot{\theta}\right|_{\theta-\Delta \theta}\right)^{2}\right]
\end{gathered}
$$

Equation (24) shows the right side of equation (14) integration. The instantaneous torque at this specific crank angle is assumed to be almost constant when the interval $\Delta \theta$ is sufficiently small. In this study, $\Delta \theta=1^{\circ} C A D$ (Crankshaft Angular Degree).

$\int_{\theta-\Delta \theta}^{\theta} \Gamma_{\text {total }}(\theta) d \theta=\frac{\Gamma_{\text {total }}(\theta-\Delta \theta)+\Gamma_{\text {total }}(\theta)}{2} \times \Delta \theta=\bar{\Gamma}_{\text {total }}(\theta) \times \Delta \theta$

The total torque is given as

$$
\bar{\Gamma}_{\text {total }}(\theta)=\frac{1}{2} \times \frac{J}{\Delta \theta}\left[\left(\left.\dot{\theta}\right|_{\theta}\right)^{2}-\left(\left.\dot{\theta}\right|_{\theta-\Delta \theta}\right)^{2}\right]
$$

Finally, the total instantaneous friction torque is given by

$$
\Gamma_{f r}(\theta)=\Gamma_{\text {total }}(\theta)-\Gamma_{\text {gas }}(\theta)-\Gamma_{\text {mass }}(\theta)-\Gamma_{\text {load }}(\theta)
$$

Through the operation of the measure of the instantaneous speed of the crankshaft using a proximity sensor, the total torque of the crankshaft is deduced. Thus, it becomes possible to estimate the friction torque and drive axillaries (so-called parasitic couples) in steady state if the resistant torque applied to the engine is known.

\section{EXPERIMENTAL SETUP}

The different manipulations have been carried out on a diesel engine test bench with turbocharger (Figure 1). The characteristics of the engine are shown in Table 1 . The motor is loaded by an eddy current dynamometer. An AVL 365C angular encoder was used, which is connected to the crankshaft. Its function is to convert the angle of the crankshaft in electrical signal, then digital, which is evaluated by a data processing system that can determine the position and speed of the shaft. The encoder sampling step is 0.1 crankshaft degree or 7200 points per cycle. The pressure measurements in the cylinder allow knowing the position of the crankshaft to establish real thermodynamic cycles and characterize combustion. The pressure sensor used is Kistler 6055B. 
The control and acquisition of the measured signals are managed by two systems. The first control system is the engine-dynamometer with the acquisition of low frequency measurements (torque, average engine speed, manifold pressure and temperature, air and fuel flow rates). The second system measures high frequency signal parameters (cylinder pressure, fuel injection pressure and crankshaft speed fluctuations). The measurement errors of the main sensors, used for the various experimental measurements, are given in Table 2.

\section{SIMULATION AND EXPERIMENTAL RESULTS}

The first part of this work is devoted to the simulation results of the cylinder pressure of the K9K diesel engine. A comparison is made between the measurement results and those obtained using a thermodynamic model. The second part is dedicated to the presentation of the results of the simulation series derived from the engine dynamics model, performed to have the different torques that act on the entire crankshaft. The different torques are:

- the total torque calculated from the fluctuation of the measured rotational speed of the crankshaft,

- the moment of inertia (mass torque),

- the indicated torque (couple of gas),

- the total instantaneous friction torque.

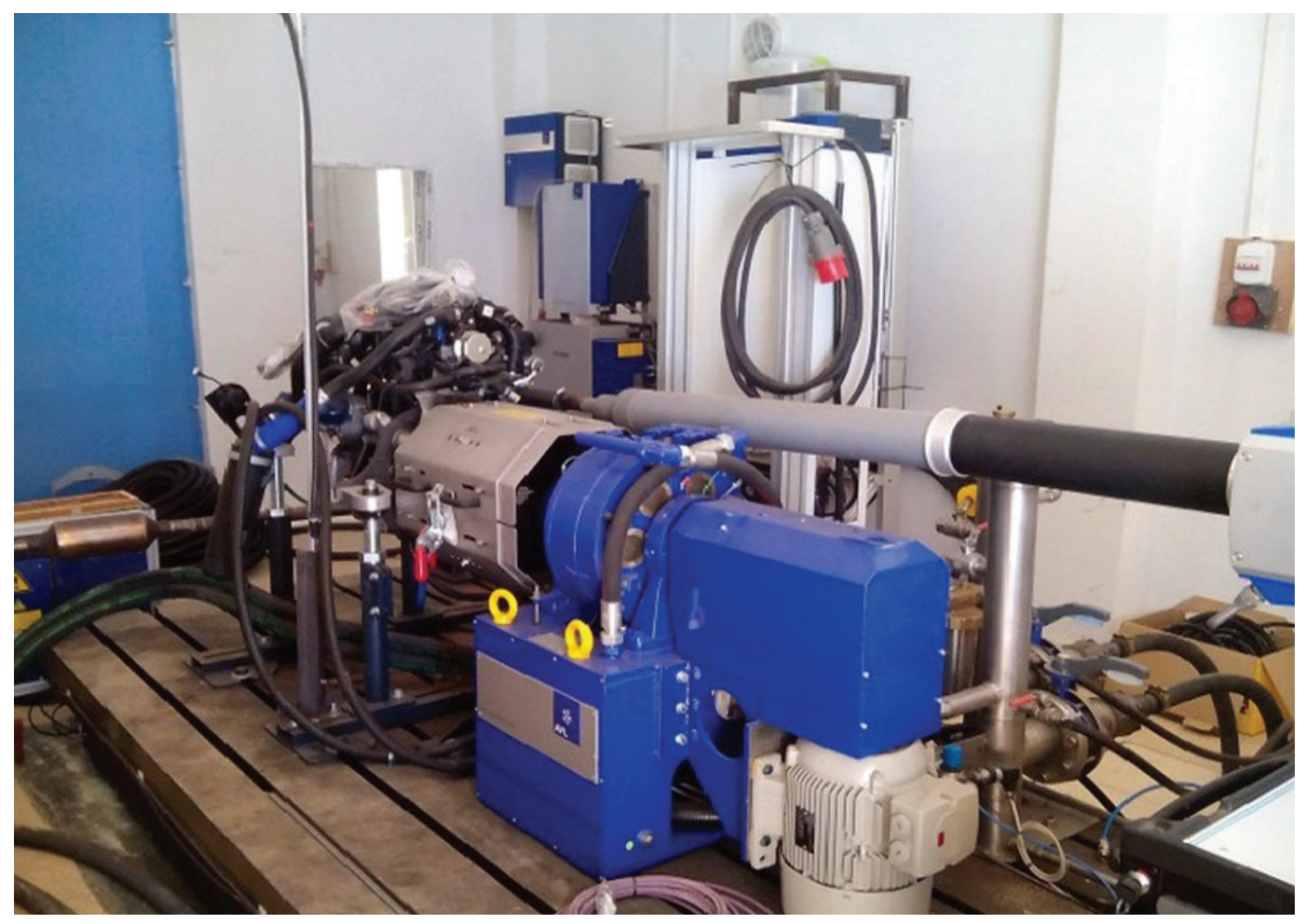

Figure 1. View of the engine test bench (Seddak et al., 2018). 
Table 1. Engine specifications (Seddak et al., 2018).

\begin{tabular}{|c|c|c|}
\hline Parameters & Specifications & Unit \\
\hline Engine type & K9K & \\
\hline $\mathrm{N}^{\circ}$ of cylinders & Four cylinders & \\
\hline $\mathrm{N}^{\circ}$ of strokes & Four strokes & \\
\hline Max. power & 80 & $\mathrm{~kW}$ \\
\hline Max. torque & 240 & $\mathrm{Nm}$ \\
\hline Cylinder bore & 76 & $\mathrm{~mm}$ \\
\hline Bowl depth & 14 & $\mathrm{~mm}$ \\
\hline Stroke length & 80.5 & $\mathrm{~mm}$ \\
\hline Compression ratio & 15.3 & \\
\hline
\end{tabular}

Table 2. Sensor characteristics.

\begin{tabular}{|c|c|c|c|}
\hline Parameter & Sensor and type & Measuring range & Measurement error \\
\hline In-cylinder pressure $\left(p_{c y l}\right)$ & $\begin{array}{c}\text { Kistler 6055BB80+Ampli. } \\
\text { Kistler 5011B }\end{array}$ & $0 \sim 150 \mathrm{bar}$ & $<2 \%$ \\
\hline $\begin{array}{c}\text { Instantaneous crankshaft } \\
\text { speed }(\dot{\theta})\end{array}$ & $\begin{array}{c}\text { Engine mounted AVL } \\
\text { encoder 365C }\end{array}$ & $50 \sim 20000 \mathrm{tr} / \mathrm{min}$ & $\pm 3 \mathrm{rpm}$ \\
\hline
\end{tabular}

\section{CYLINDER PRESSURE RESULT}

Figure (2) shows a comparison between the cylinder pressure calculated and measured during an engine cycle for more details see (Seddak et al., 2018). The results are obtained by simulation for different engine operating conditions:

a) $1100 \mathrm{rpm}$ at load of $67.5 \mathrm{Nm}$,

b) $1400 \mathrm{rpm}$ at load of $121 \mathrm{Nm}$,

c) $1700 \mathrm{rpm}$ at load of $166.3 \mathrm{Nm}$.

It can be noted that the experimental measurements values are in the order of those given by the numerical values predicted by the model. These results show the following deviations:

- for $1100 \mathrm{rpm}$ the peak-to-peak difference is $1.6 \%$ with a delay of 1 degree,

- for $1400 \mathrm{rpm}$ the peak-to-peak difference is $2 \%$ with a delay of 3 degrees,

- for $1700 \mathrm{rpm}$ the peak-to-peak difference is $4.2 \%$ with a delay of 1 degree.

Most prediction errors come from simplifying assumptions. Despite this, the model can be considered sufficiently precise for the control analysis. The numerical results of the cylinder pressure are then integrated into the dynamic model (second part) to estimate the total lost instantaneous friction torque described by equation (26). 


\section{THE DYNAMIC MODEL}

Figure (3) shows the flow chart for estimating the friction torque. This method will first estimate the total torque exerted on the crankshaft from the rotational speed measured using the dynamic model. Then, the torques gas, inertia, and load are subtracted.

The measured angular velocity data contains high frequency components. These frequency components are due to the high frequency torsional vibration of the crankshaft for different natural frequencies, and random noise from unknown sources. For the resolution of the equations necessary for the calculations of the different torques, the data of the angular velocity must be differentiated once to determine the angular acceleration.

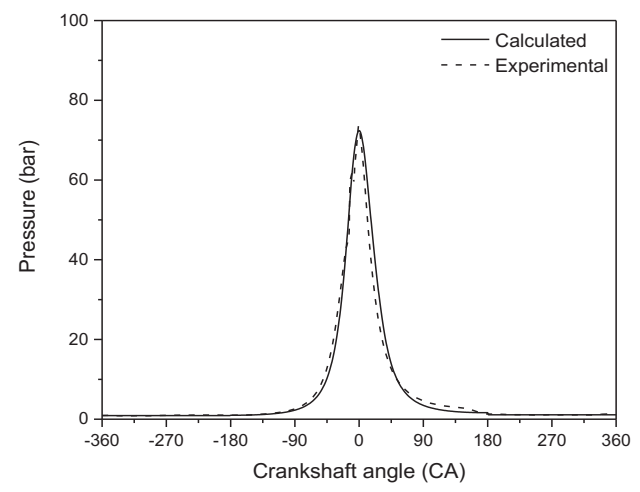

(a)

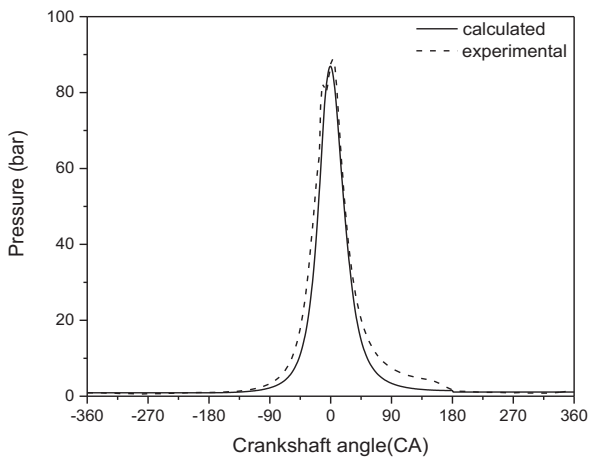

(b)

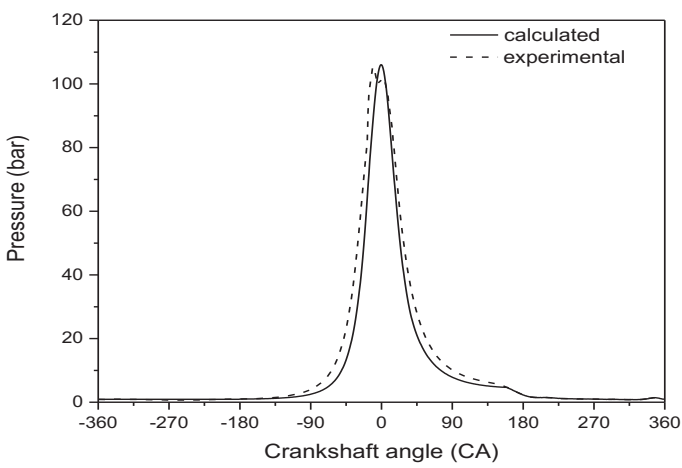

(c)

Figure 2. Comparison between measured and simulated in-cylinder pressure. (a) $1100 \mathrm{rpm}$ at load of $67.5 \mathrm{Nm}$, (b) $1400 \mathrm{rpm}$ at load of $121 \mathrm{Nm}$, and (c) $1700 \mathrm{rpm}$ at load of $166.3 \mathrm{Nm}$.

If the raw data (gross speed signal) was used in the calculation, the high frequency components would be greatly magnified by the subsequent differentiation of the angular velocity. Therefore, the highest frequency components are filtered before differentiation to increase the signal/noise ratio in the resolution of the torque equations. The Fast Fourier Transform (FFT) filter with a 12-point window was considered a filtering method in this study. The filter 
allowed us to separate between the higher order torsional vibration components and the lower frequency components, which are of interest (Fig.4).

The engine inertia is shown in Figure (5). The inertia of the crank assembly is not constant, but it is a function of the crankshaft angle. Due to the fixing of the large end of the connecting rod with the crankshaft, the maximum inertia of the crank assembly is close to $\frac{\pi}{2}$ and $\frac{3 \pi}{2}$ of the angular position of the crankshaft, and the minimum is close to 0 and $\pi$.

Figure (6) illustrates the evolution of instant crankshaft acceleration under steady-state conditions. For the calculation of the instantaneous acceleration, the crankshaft velocity measured after filtering was used.

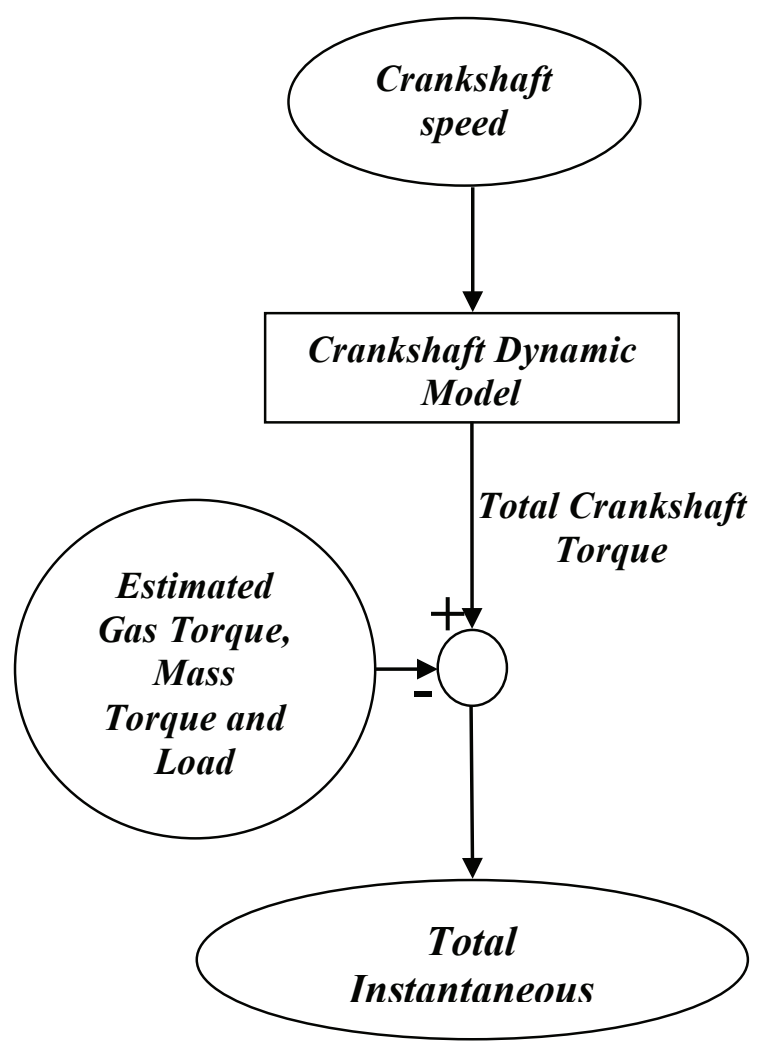

Figure 3. The flowchart of the estimation algorithm.

The torque of inertia (of mass), $\Gamma_{\text {mass }}$, is the resultant of the reciprocating movement of the piston and the head of the connecting rod (part of the connecting rod connected to the piston which describes a translation movement). Figures (7.a) and (7.b), respectively, represent the variation of the mass torque of the fourth cylinder as well as the changes in the total mass torque obtained by adding all the mass torque of all the cylinders as a function of the crankshaft angle for the three operating conditions.

The torque of inertia (mass torque) is proportional to the rotational speed of the engine. The term meaning the square of the velocity $\dot{\theta}^{2}$ in the expression of the mass torque (Equation 19) increases rapidly when the rotational 
speed of the engine increases. Therefore, for high regimes, this term will amplify the mass torque and make it much more influential in determining the total torque of the crankshaft.

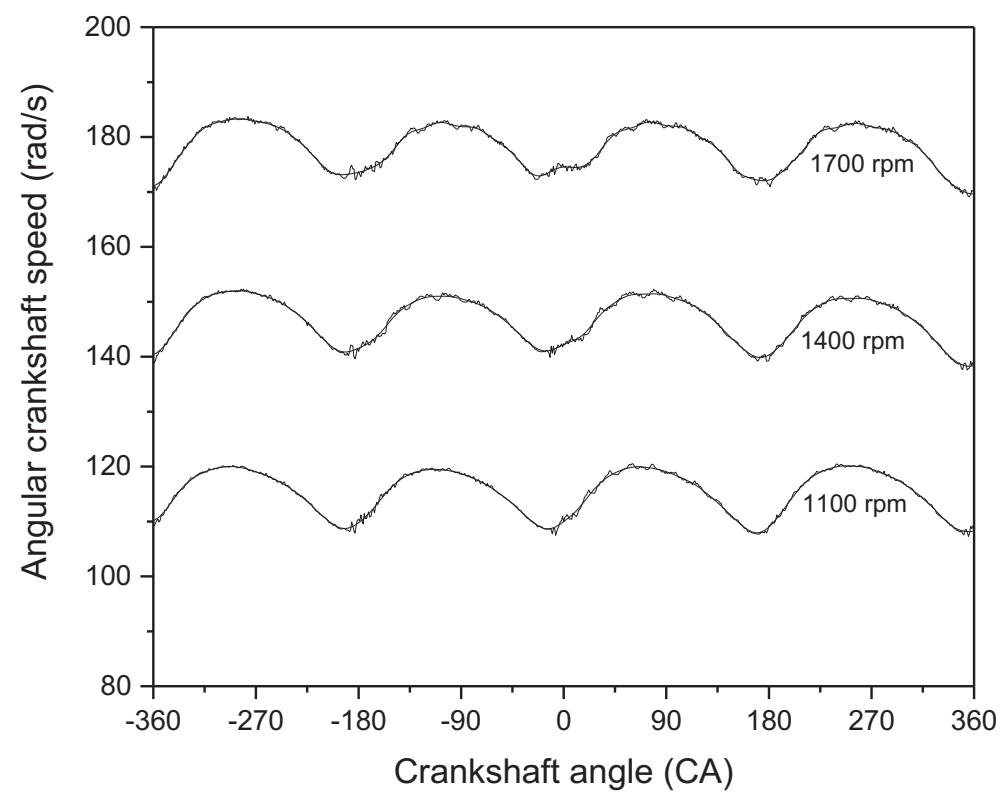

Figure 4. The measured and filtered signal of the instantaneous crankshaft speed.

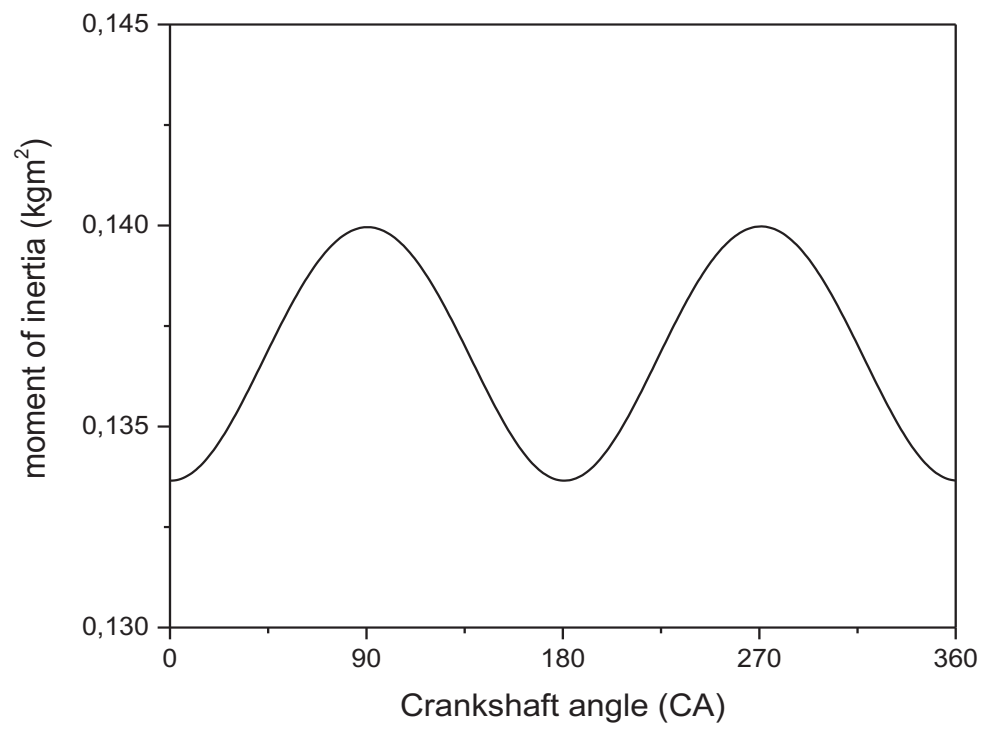

Figure 5. Inertia of the crankshaft assembly. 


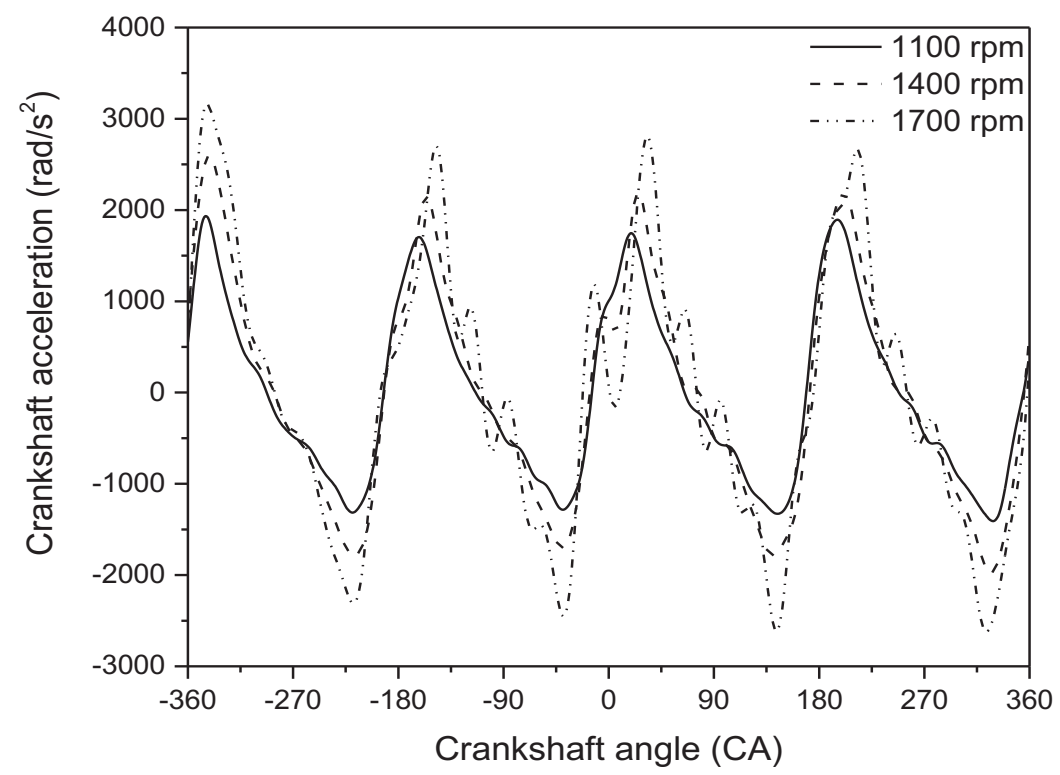

Figure 6. Estimation of instantaneous filtered acceleration of crankshaft.

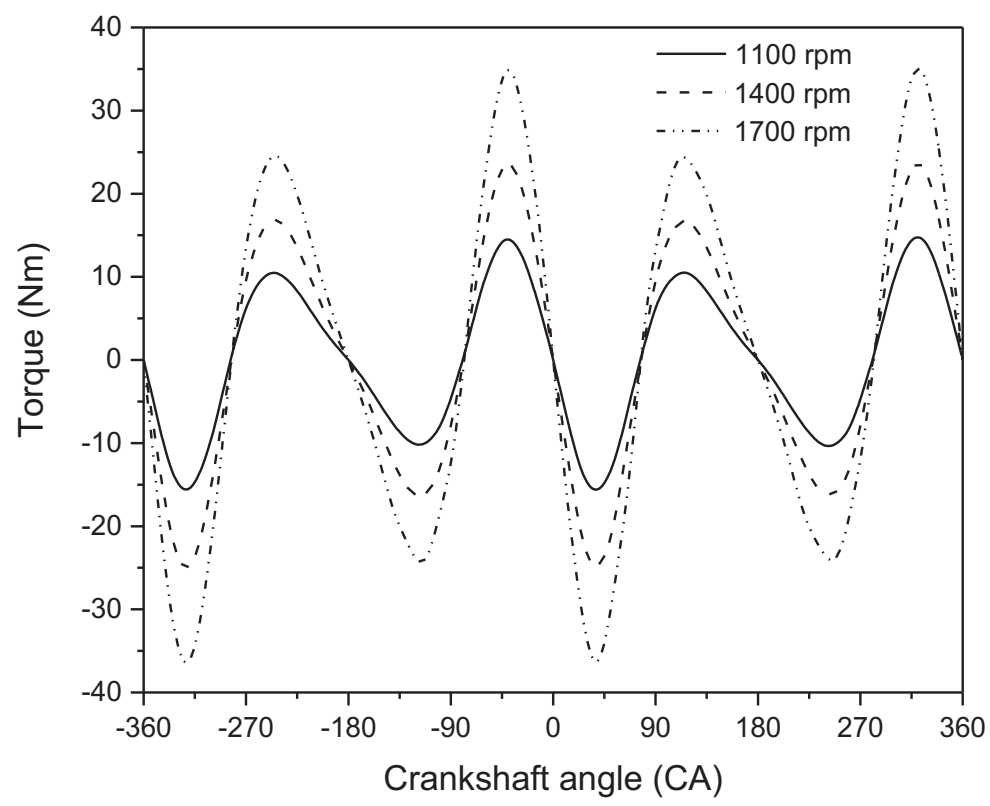

(a) 


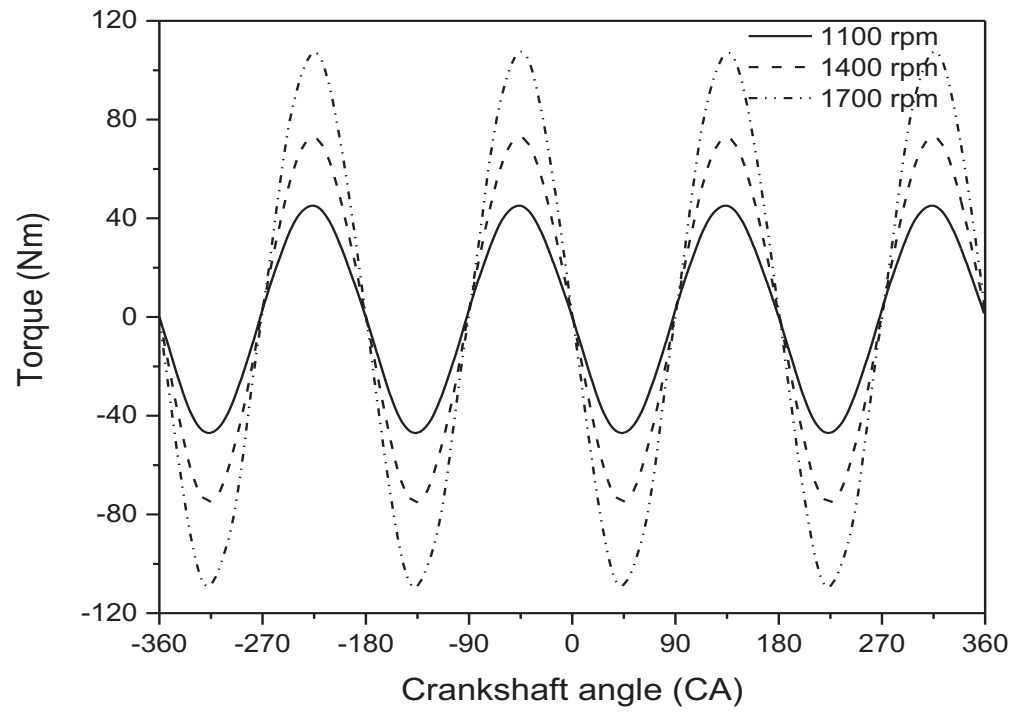

(b)

Figure 7. Variation of mass torque; a) individual cylinder and b) total mass torque.

The indicated torque, $\Gamma_{\text {gas }}$, is the result of the action of the gases on the piston. It translates the thermodynamic work transmitted to the crankshaft. In Figure (8) is shows the variation of the indicated torque calculated for each cylinder depending on the crank angle of rotation. The torque is negative, during the intake and compression strokes (between $-360^{\circ}$ and $0^{\circ}$ ). It increases considerably during the relaxation, following the high pressure of the combustion gases in the cylinder, which in turn generates significant forces on the piston. During the exhaust process, the torque decreases to become negative.

The indicated torque of the fourth cylinder plotted according to the measured cylinder pressure is compared with the calculated indicated torque of the same cylinder. It can be noted that the torque obtained by the calculation coincides well with the measured torque. The difference between the two curves and especially at the top is due to the difference between the pressure values measured and predicted by the thermodynamic model.

The sum of the indicated torques corresponding to each cylinder gives us the total torque indicated. $\Gamma_{\text {total gas }}(\theta)=\sum_{1}^{Z_{c y l}=4} \Gamma_{\text {gas }}(\theta)$. These pairs are shown in Figure (9) for the three working engine speeds considered. A good agreement is observed between the total torque indicated established from the cylinder pressure prediction and that obtained from the measured cylinder pressure. The absolute difference is less than $10 \%$ due to the normal difference between calculated and measured cylinder pressures.

Figure (10) shows the comparison between the total torque obtained from the measurement of the instantaneous speed of the crankshaft for the three operating conditions. The total torque is proportional to the speed of rotation.

It must be realized that the load torque exhibits fluctuations in an engine cycle even under the stationary conditions. An example of the instantaneous measurement of the load torque for the three speeds of rotation is shown in Figure (11). 
Figure (12) shows the total instantaneous friction torque at different rotational speeds of the crankshaft. It also shows that the total friction torque increases with the speed of rotation of the crankshaft.

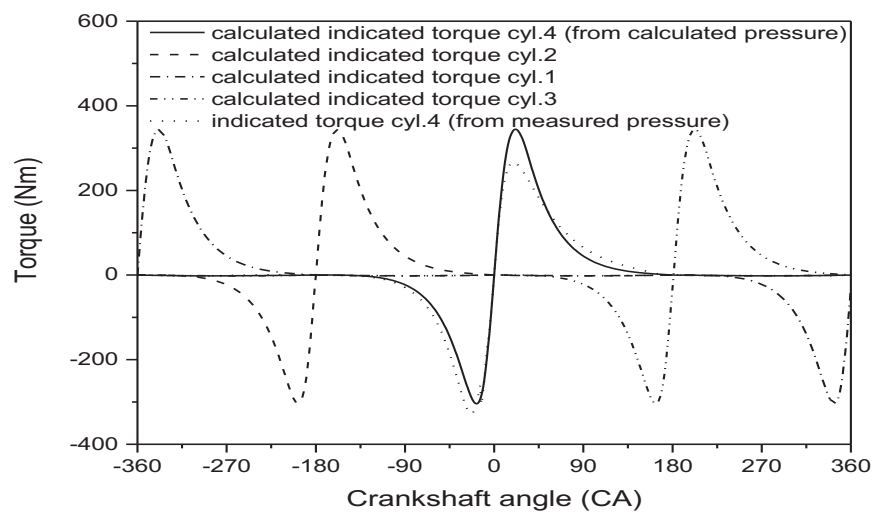

(a)

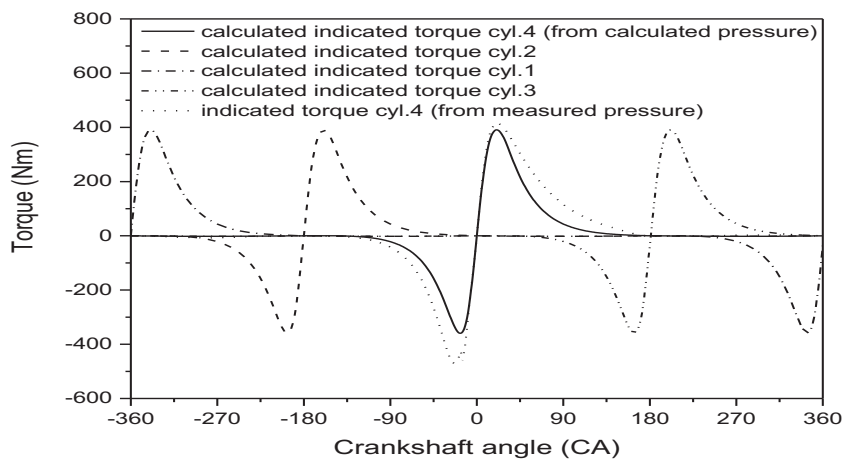

(b)

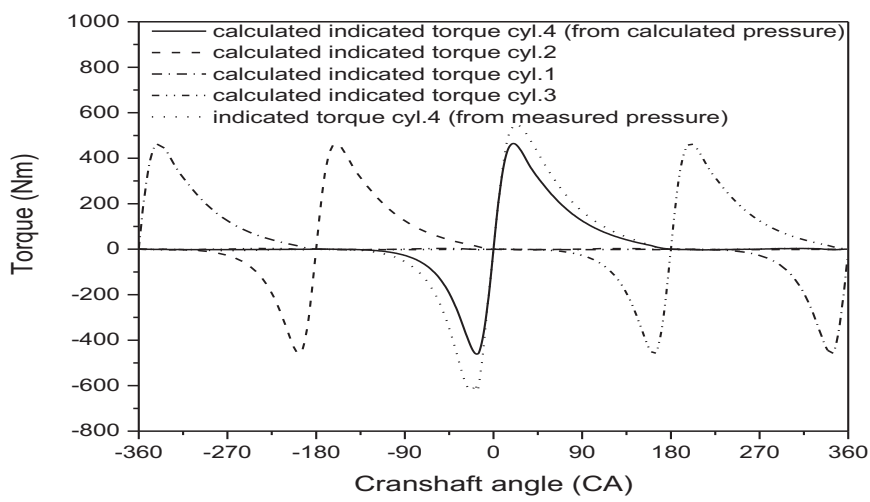

(c)

Figure 8. The predicted gas torque for the fourth cylinder at different engine operating conditions: (a) $1100 \mathrm{rpm}$ at load of $67.5 \mathrm{Nm}$, (b) $1400 \mathrm{rpm}$ at load of $121 \mathrm{Nm}$, and (c) $1700 \mathrm{rpm}$ at load of $166.3 \mathrm{Nm}$. 


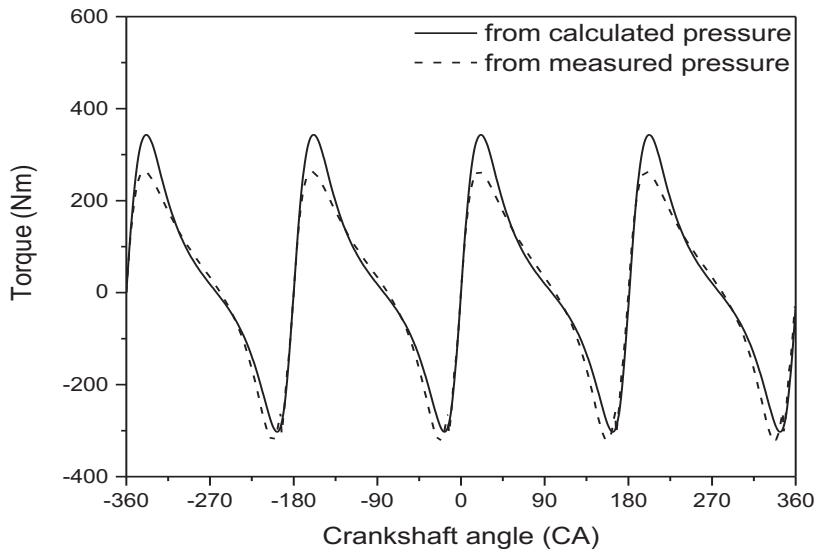

(a)

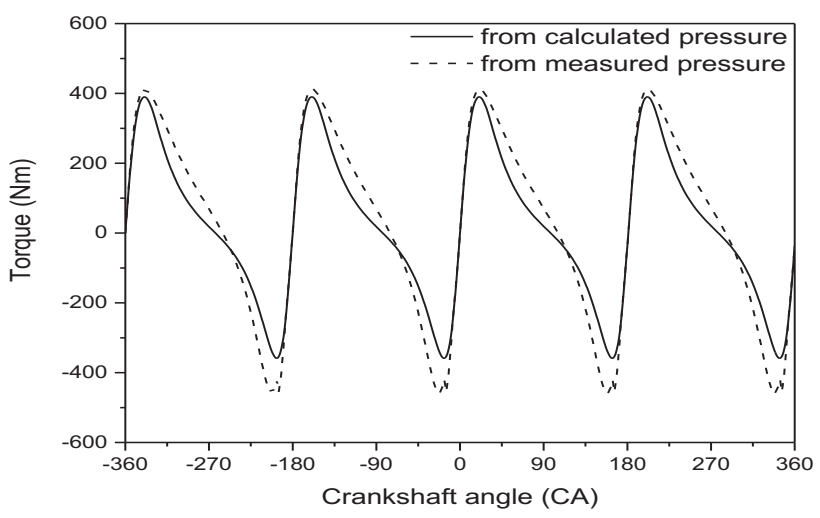

(b)

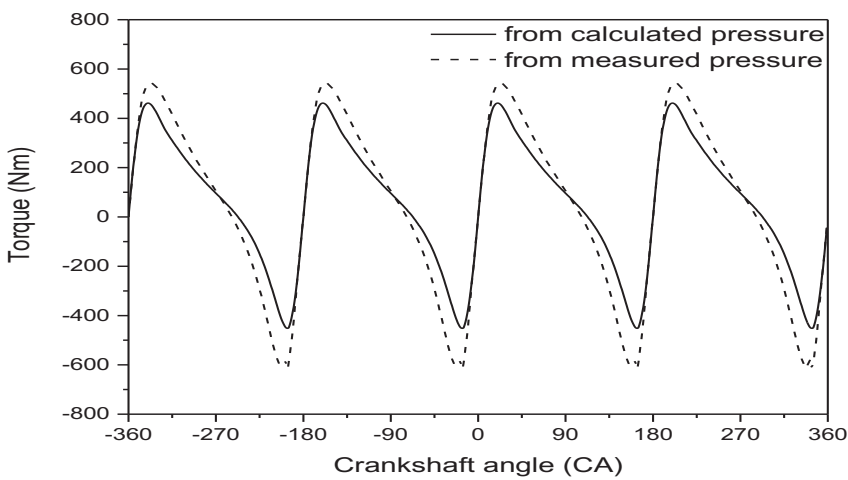

(c)

Figure 9. The engine total indicated (gas) torque at different engine operating conditions: (a) $1100 \mathrm{rpm}$ at load of $67.5 \mathrm{Nm}$, (b) $1400 \mathrm{rpm}$ at load of $121 \mathrm{Nm}$, and (c) $1700 \mathrm{rpm}$ at load of $166.3 \mathrm{Nm}$. 
For a given speed, this torque is very important in the vicinity of the Top Dead Center (TDC) of each cylinder because of the preponderant effect of the strong cylinder pressure. Indeed, before the $T D C$, the increase in torque is due to the fact that the pressure of the gases is expressed as a resistance to movement of the piston and thus causes an increase in the friction torque.

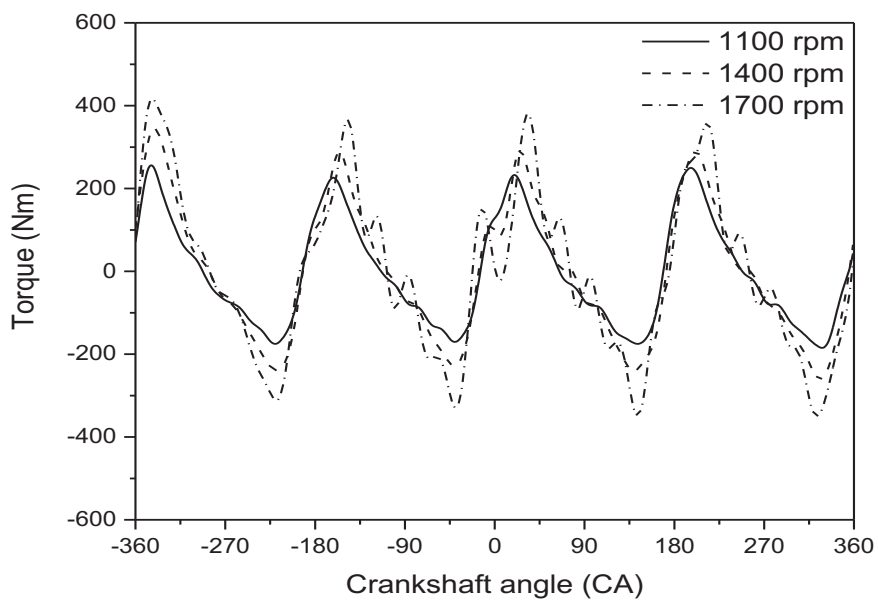

Figure 10. Variation of measured total torque.

At the TDC, the torque passes through a minimum; in fact, a piston stopping the friction it generates becomes zero. The total friction torque then becomes equal to that of the drive of the bodies and the friction of the bearings. After the TDC, the increase in the friction torque is due to the fact that one of the cylinders is in the expansion phase.

In regions distant from TDC of the end of compression, the total friction torque becomes substantially constant and low. This is due to the preponderance of the effect of crankshaft rotation speed in these regions.

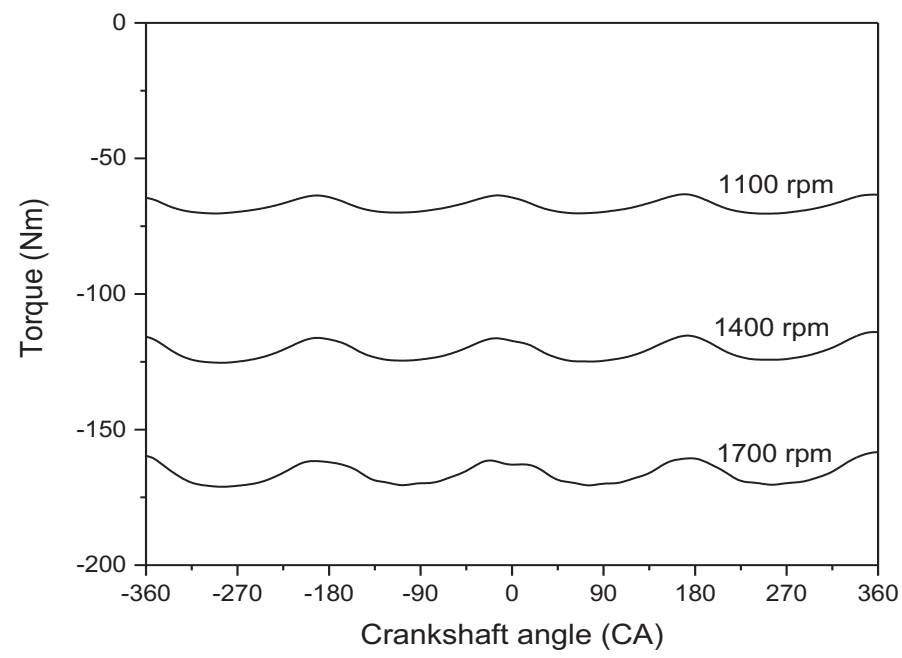

Figure 11. Variation of load torque. 


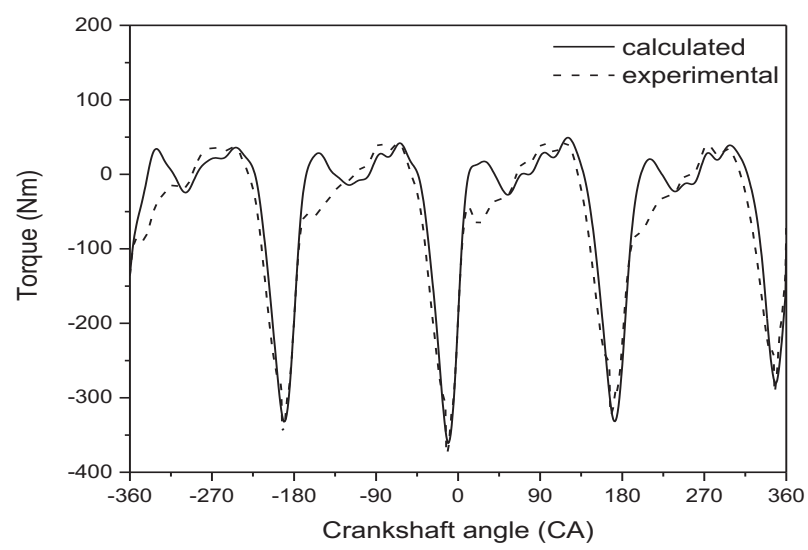

(a)

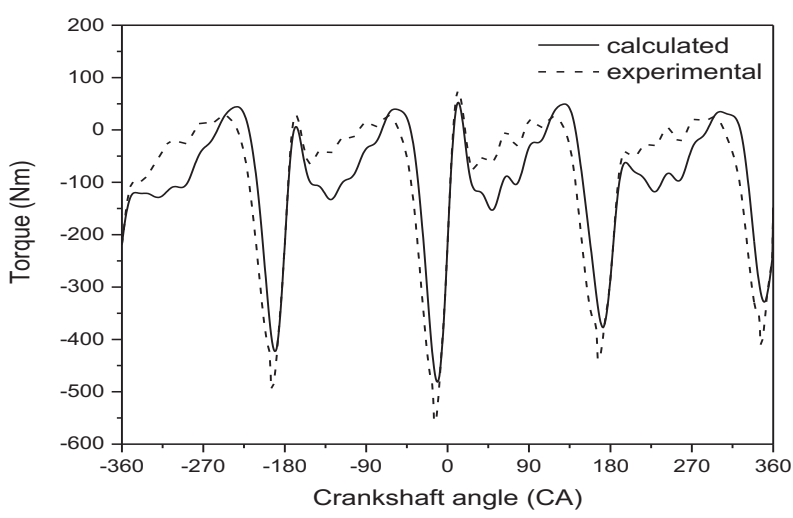

(b)

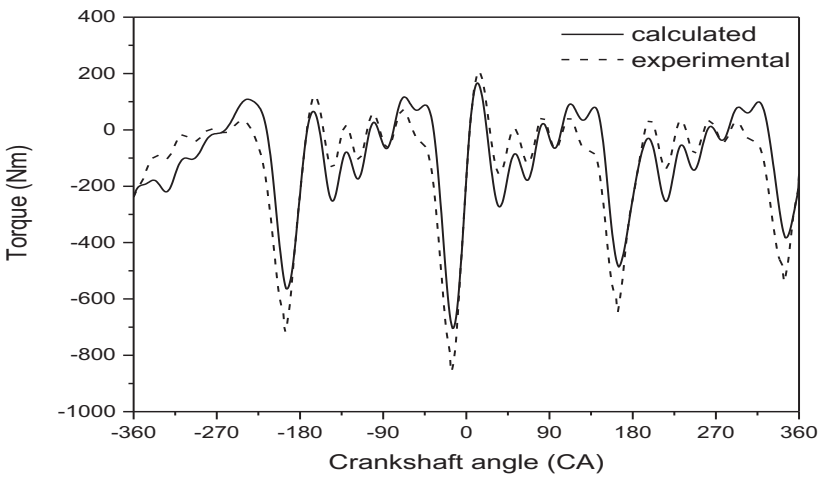

(c)

Figure 12. Comparison between measured and predicted of the engine total friction torque. (a) $1100 \mathrm{rpm}$ at load of $67.5 \mathrm{Nm}$, (b) $1400 \mathrm{rpm}$ at load of $121 \mathrm{Nm}$, and (c) $1700 \mathrm{rpm}$ at load of $166.3 \mathrm{Nm}$. 


\section{CONCLUSION}

This study investigates a method for estimating total instantaneous friction torque for a four-cylinder IC engine. Total instantaneous friction torque was calculated based on instantaneous crankshaft angular velocity measurements and cylinder pressure prediction based on a simplified thermodynamic approach.

For the calculation of the total torque as a function of the instantaneous speed of the crankshaft, the dynamic model of a rigid body of the crankshaft of the engine was used. To estimate the cylinder pressure of the engine, the phenomenological model (0-D) is used in the steady state. By obtaining the total torque, it is possible to obtain the instantaneous friction torque. Then, the numerical simulation was validated with respect to the experimental results. The main conclusions are as follows:

- The inertia variations of the crank shaft assembly are included.

- Profiles of the cylinder gas pressure and the different torques predicted by the model, during steady-state cycles, are in good agreement with measurements.

- The technique is applied to the problem of estimating total instantaneous friction torque from measurements of crankshaft angular velocity and displacement. It is shown that the estimated torque has a good accuracy when compared to experimental data. The results are encouraging indicating promise for real-time applications and for use as an on-board diagnostic tool.

\section{REFERENCES}

Wong, V. W. \& Tung, S.C., 2016. Overview of automotive engine friction and reduction trends-Effects of surface, material, and lubricant-additive technologies. Friction. 4 (1): 1-28.

Heywood, J. B. 1988. Internal Combustion Engine Fundamentals. McGraw-Hill series in mechanical engineering.

Morris, N., Rahmani, R., Rahnejat, H., King, P. \& Fitzsimons, B. 2013. The influence of piston ring geometry and topography on friction. P I Mech Eng J-J 227: 141-153.

Ciulli, E., Rizzoni, G. \& Dawson, J. 1996. Numerical and Experimental Study of Friction on a Single Cylinder CFR Engine. SAE Technical Paper 960357.

Kouremenos, D., Rakopoulos, C., Hountalas, D. \& Zannis, T. 2001. Development of a Detailed Friction Model to Predict Mechanical Losses at Elevated Maximum Combustion Pressures. SAE Technical Paper.

Thring, R. 1992. Engine Friction Modeling. SAE Technical Paper 920482.

Miura, A. \& Shiraishi, K., 1989. Investigation of Main Bearing Friction in a Diesel Engine. SAE Technical Paper 890140.

Leong, D.K. 2004. Investigations of Friction Losses in Automotive Internal Combustion Engines, PhD Thesis. University of Nottingham.

Meng, X., Fang, C. \& Xie, Y. 2016. Transient tribodynamic model of piston skirt-liner systems with variable speed effects. Tribol Int 94: 640-651.

Livanos, G. \& Kyrtatos, N. 2006. A Model of the Friction Losses in Diesel Engines. SAE Technical Paper.

Zweiri, Y. H., Whidborne, J.F. \& Seneviratne, L.D. 1999. Instantaneous friction components model for transient engine operation. Proc. Inst. Mech. Engrs., Journal of Automobile Engineering, 214.

Holmberg, K., Andersson, P. \& Erdemir, A. 2012. Global energy consumption due to friction in passenger cars. Tribol Int 47: 221-234. 
Bishop, I. 1964. Effect of Design Variables on Friction and Economy. SAE Technical Paper 640807.

Patton, K., Nitschke, R. \& Heywood, J.B. 1989. Development and Evaluation of a Friction Model for SparkIgnition Engines. SAE Technical Paper 890836.

Taraza, D., Henein, N., A., Ceausu, R. \& Bryzik W. 2007. Engine friction model for transient operation of turbocharged, common rail diesel engines. SAE Paper Warrendale, PA.

Iserman, R. 2014. Engine Modeling and Control: Modeling and Electronic Management of Internal Combustion Engines. Springer, Berlin.

Sakhrieh, A., Abu-Nada, E., Al-Hinti, I., Al-Ghandoor, A. \& Akash, B. 2012. Computational thermodynamic analysis of compression ignition engine, Int. Commun. Heat Mass Transf, 37: 299-303.

Ferguson, C. \& Kirkpatrick, A. 2001. Internal Combustion Engines: Applied Thermosciences. Wiley, New York.

Pulkrabek, W. 2004. Engineering Fundamentals of the Internal Combustion Engine, 2nd edn. Pearson PrenticeHall, Upper Saddle River.

Sonntag, R., Borgnakke, C. \& VanWylen, G. 1998. Fundamentals of Thermodynamics, 5th edn. Wiley, New York. Kiencke, U. \& Nielsen, L. 2000. Automotive Control Systems for Engine, Driveline and Vehicle. Springer, London.

Rakopoulos, C., D., \& Giakoumis, E.,G. 2009. Diesel Engine Transient Operation: Principles of Operation and Simulation Analysis. Springer, London.

Seddak, M., \& Liazid, A. 2018. An Experimental Study on Engine Dynamics Model Based on Indicated Torque Estimation, Arab J Sci Eng, 43. 